\title{
Investigation of energy consumption trends in petrochemical plants for the management of resource saving
}

\author{
A. I. Shinkevich ${ }^{*}$, T. V. Malysheva ${ }^{1}$, I. A. Zaraichenko ${ }^{1}, A$. A. Lubnina ${ }^{1}$, G. R. Garipova ${ }^{1}$, and M. M. Sharafutdinova ${ }^{1}$ \\ ${ }^{1}$ Kazan National Research Technological University, Kazan, Russia
}

\begin{abstract}
The relevance of the research topic is due to the study of the important problem of improving the energy efficiency of the economy and the meso and micro levels. In the conditions of the development of an innovative economy, energy saving becomes one of the main factors for increasing the economic efficiency and economic security of industrial enterprises and complexes. The article discusses the main aspects of the organization of energy-saving environmental production systems. The factors affecting the energy efficiency of the production process from the standpoint of logistics, including the processes of storage, storage and transportation of products within an industrial enterprise, are summarized. As a criterion of energy saving in logistics chains, the coefficient of consumption of energy resources spent per unit of production is given. The analysis of the dynamics of fuel and energy costs per unit of output by the types of activities of petrochemical plants of the Republic of Tatarstan was carried out. The specificity of the level of fuel and energy costs by type of activity is shown, depending on the specifics of production and products. The variation of energy consumption data by types of petrochemical production activities for 10 years has been calculated. The prospects for reducing the energy intensity of petrochemical enterprises in the context of the liberalization of the market of electric energy and power are considered. The materials of the study can be used in managing the development of the real sector of the economy, the service sector, both at the enterprise services level and in government structures. In addition, the proposed methodology is appropriate for assessing the level of resource-saving production, building innovative energy-saving development strategies, and developing a mechanism for targeted actions for the rational use of resources.
\end{abstract}

\section{Introduction}

The high level of energy intensity of production of domestic petrochemical enterprises is one of the most important reasons constraining the increase of their competitiveness in the global market. The solution to this problem is of particular importance. This is primarily due to a decrease in the demand for products from partners and a reduction in selling prices for this reason.

The organization of energy-saving ecological production systems is a combination of technological means and processes with minimal energy consumption at all stages of the production cycle with the least impact on ecosystems. The problem of saving and rational use of energy resources is also important from the point of view of the ecological logistics chain. Logistics allows you to adjust the consumption of material resources by managing stocks and consumption of raw materials and energy sources. In a complete chain of logistics, the strategic goal is to save energy, minimize the cost of fuel and energy. Energy saving in logistics chains is to reduce the consumption of fuel and energy resources spent per unit of production.

When considering the main factors and sources of economy of resources, it is necessary to clearly define the possibilities of logistics in this process. Costs of production and sales of products are classified into costs directly related to the production process, and costs associated with the storage, warehousing and transportation of raw materials and finished products. As for the production process, from the standpoint of logistics, there is the possibility of influencing the reduction of costs during storage, storage and transportation of products within an industrial enterprise. At the same time, there are no tools to reduce the costs of material resources coming from the cooperation.

\section{Literature review}

Problems of the development of modern energy in industry are examined in the works of scientists in different directions, including the organization and management of energy technologies [1], assessment of energy use factors across the economy [2], the impact of restrictions on electricity prices [3], regulation of incentives for investment in smart grid technologies [4], sustainable development of competitive enterprises through the implementation of an energy saving strategy [5]. directions of improving energy efficiency at the meso and micro levels of the economy [6], energy

\footnotetext{
*Corresponding author: ashinkevich@mail.ru
} 
efficiency of the chemical production system [7], organization of production of competitive petrochemical products [8].

There are developments of scientists in the field of energy efficiency of the economy, namely, the formation of a network model of the value chain based on the integration of competitive enterprises in innovationoriented inter-sectoral clusters [9], an integrated system for controlling production processes [10], prioritizing interdependent production processes using the Leontief model "input-output" [11], development of energy innovations and energy policy $[12\}$.

The fundamentals of energy efficiency analysis and modeling of resource-saving systems are presented in the context of the following areas: evaluation of quality improvement methods in terms of production and supply chain [13], productivity modeling based on the cost analysis of the product development process architecture [14], modeling of complex logistics service processes [15] , assessment and review of the prospects for the complexity of innovation in the field of energy saving [16], assessment of the achievement of reliability in industrial enterprises [17].

Analysis of the work of scientists on the organization and management of energy saving and on improving the energy efficiency of enterprises has shown that the mechanisms and tools used to manage energy saving are currently not fully taking into account the possibilities of economic integration of the participants of the energy saving business process in the distribution and implementation of energy saving measures. In some cases, this does not allow implementing scientificallybased recommendations for improving energy saving and reduces the energy efficiency indicators of industrial enterprises. In this regard, the task of developing an organizational mechanism for improving the energy efficiency of enterprises based on an energy audit procedure is essential for the development of the theoretical foundations of energy conservation management.

\section{Results and discussions}

Consider the dynamics of fuel and energy costs per 1 ruble of output (energy consumption of products) by type of petrochemical industry of the Republic of Tatarstan. The following components are referred to fuel and energy resources: electric energy, thermal energy, natural gas, fuel oil, coal, gasoline, diesel fuel, water, other fuels (table 1).

The level of costs for fuel and energy differs by type of activity, which, first of all, is due to the specifics of production and products. Traditionally, the largest amount of energy consumption is observed in the production of chemicals -0.109 rubles per 1 ruble of products in 2017 (enterprises - representatives: "Kazanorgsintez", "Nizhnekamskneftekhim", "Nefis Cosmetics", "Hiton", "KZSK-Silicon", "Ammoni" and others).

The energy consumption of enterprises producing petroleum products (enterprises - representatives: "TaifNK", "Taneco", etc.) and enterprises producing rubber and plastic products (enterprises - representatives: "Nizhnekamskshina", "KVART", "Polymer-NKNH", "Rototek-Kama", "Danafleks", "Kazan plant "EvroPlast", "SafPlast", "Nizhnekamskii zavod shin TCMK" and others).

The lowest value of fuel, energy and water consumption is noted in the extraction of crude oil and natural gas -0.028 rubles per 1 ruble of products in 2017 (enterprises - representatives: "Tatneft", "Tatex", "Tatnefteotdacha", "Transoil", "Kondurchaneft", "Geology", "Ideloil", "Sheshmaoil", "SMP-Neftegaz", "Geotech", "Aloil" and others).

A graphic depiction of the dynamics of the energy consumption of petrochemical plants allows you to see the trend in fuel, energy and water consumption per ruble produced (Figures 1-4). A fairly stable situation is observed in the extraction of crude oil and natural gas. For 10 years (2008-2017) the standard deviation for the studied data series is 0.031596 . The decrease in the selling price of oil in 2013 affected the energy consumption. Excluding the energy consumption parameter, the standard deviation will be 0.002179 . [18].

Table 1. The level of energy consumption of petrochemical industries (fuel, energy and water per 1 ruble of output).

\begin{tabular}{|c|c|c|c|c|c|c|c|c|c|c|}
\hline & \multicolumn{10}{|c|}{ Energy and fuel per 1 ruble of output, rubles (energy consumption of production) } \\
\hline & 2008 & 2009 & 2010 & 2011 & 2012 & 2013 & 2014 & 2015 & 2016 & 2017 \\
\hline $\begin{array}{l}\text { Extraction of crude oil } \\
\text { and natural gas }\end{array}$ & 0.027 & 0.026 & 0.026 & 0.023 & 0.022 & 0.126 & 0.026 & 0.025 & 0.029 & 0.028 \\
\hline $\begin{array}{l}\text { Production of coke } \\
\text { and petroleum product }\end{array}$ & 0.026 & 0.026 & 0.021 & 0.016 & 0.017 & 0.022 & 0.025 & 0.024 & 0.030 & 0.032 \\
\hline $\begin{array}{l}\text { Production of } \\
\text { chemicals and } \\
\text { chemical product }\end{array}$ & 0.120 & 0.168 & 0.143 & 0.106 & 0.099 & 0.118 & 0.116 & 0.100 & 0.100 & 0.109 \\
\hline $\begin{array}{l}\text { Production of rubber } \\
\text { and plastic products }\end{array}$ & 0.151 & 0.066 & 0.058 & 0.051 & 0.048 & 0.047 & 0.052 & 0.040 & 0.035 & 0.036 \\
\hline
\end{tabular}




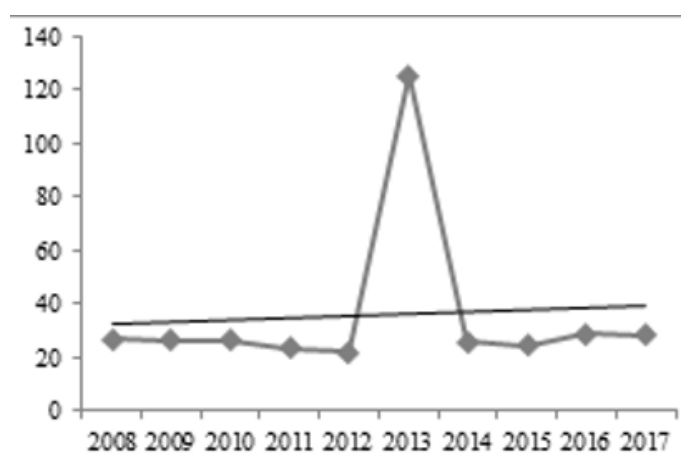

Fig. 1. Dynamics of energy consumption in the extraction of crude oil and natural gas (energy per 1 thousand rubles of production).

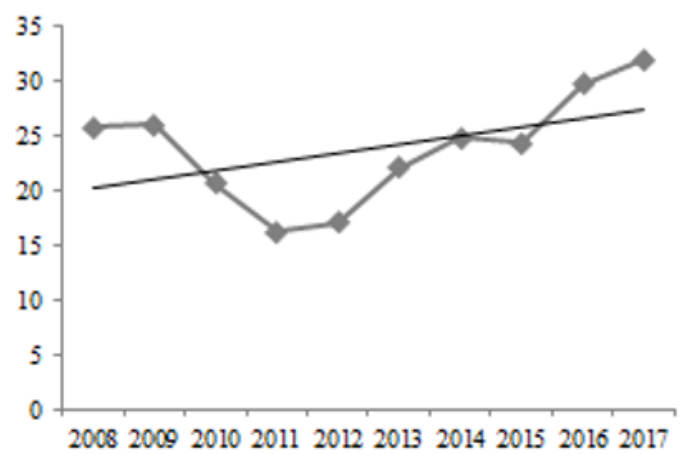

Fig. 2. Dynamics of energy consumption in the production of petroleum products (energy per 1 thousand rubles of production).

The upward trend in fuel and energy consumption is noted in the production of petroleum products. From 2008 to 2017, the growth rate of fuel, energy and water consumption per 1 thousand rubles of output produced was $123.1 \%$. The standard deviation for the studied data series is 0.005026 . This situation requires more study. The introduction of new modern production for the analyzed decade has significantly changed the level of technological effectiveness of this industry, increased its internal and external competitiveness. However, the specific consumption of fuel and energy resources increased. The reason may be both the growth of regulatory energy costs, due to the release of new types of products, and the lack of efficiency in the implementation of energy and resource saving policies in the supply chains of enterprises in the industry $[19,20]$.

In the production of chemicals and chemical products, the reduction in specific fuel consumption and energy in 2008-2017 amounted to 9.2\%. The standard deviation for the studied data series is in the range of 0.022004 . Peak values of the indicator are observed in 2009-2010 associated with the global economic and financial crisis of 2008, the loss of markets for products, reduced output, loss of flexibility and conductivity formed logistics chains.

A similar situation is observed in the production of rubber and plastic products. In general, for the period from 2008 to 2017, the reduction in specific fuel and energy consumption was 4.2 times. At the same time, excluding the peak value of 2008 , the decline is 1.8 times. The standard deviation for 2009-2017 was in the range of 0.0100 . Unlike other types of chemical industries, the dynamics of specific fuel and energy consumption are stable and negative.

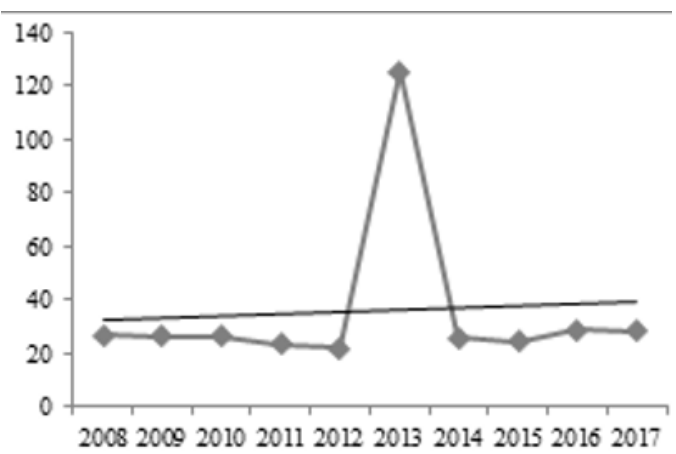

Fig. 3. Dynamics of energy consumption in the production of chemical products (energy per 1 thousand rubles of production).

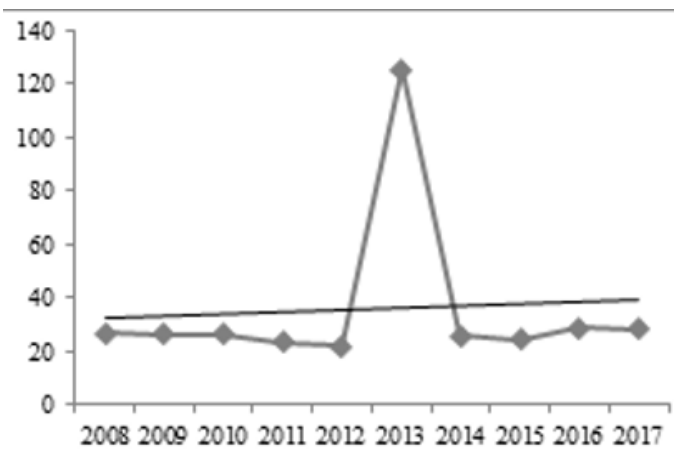

Fig. 4. Dynamics of energy consumption in the production of rubber and plastic products (energy per 1 thousand rubles of production).

Energy savings in logistics chains is to reduce the consumption of fuel and energy resources spent per unit of production. The importance of resource conservation in logistics chains is determined by:

1) an increase in the cost of production in the process of bringing it to the final consumer;

2) the proportion of material costs in the total cost of logistics.

Directly in the production process, the impact of logistics decisions on the economy of material resources is limited. Energy saving in production is determined mainly by the technology and consumption rates of raw materials of a particular production process. At the same time, procedures related to warehousing, storage and transportation within the enterprise relate to logistics services and depend on the effectiveness of the logistics decisions made.

\section{Conclusions}

Thus, the problems of minimizing energy losses, saving production and logistics resources are relevant and have a continuous nature. First, increasing the scale of production increases the volume of consumed raw materials, materials, fuel and energy resources, as well as the number of labor resources that ensure the 
reproduction process. Secondly, the depletion of mineral reserves increases the cost of raw materials and materials, which is directly proportional to the price of semi-finished and final products.

The study revealed the main trends in the energy consumption of petrochemical plants in order to determine the level of development and efficiency of resource-saving technologies at the enterprises of the petrochemical complex of the Republic of Tatarstan. Traditionally, the largest amount of energy consumption is observed in the production of chemicals - 0.109 rubles per unit of production. At the level of 0.036 rubles is the energy consumption of enterprises for the production of petroleum products and enterprises for the production of rubber and plastic products. The lowest value of fuel, energy and water consumption is noted in the extraction of crude oil and natural gas - 0.028 rubles per unit of production. Practically for all types of resources with existing technologies and the organization of the movement of material flow in logistics chains there are losses associated with the use of energy resources in production, transportation and consumption.

To date, the energy market has almost completely formed new conditions and opportunities to improve the efficiency of energy resources, not only through the use of internal energy reserves, but also as a result of the realization of new opportunities provided to consumers of energy products in a liberalized electricity and capacity market.

\section{References}

[1] L. Argote, M. Hora, Organizational Learning and Management of Technology. Production and Operations Management, 26(4), 579-590 (2017)

[2] H. Wang, B.W. Ang, B. Su, Assessing drivers of economy-wide energy use and emissions: IDA versus SDA. Energy Policy, 107, 585-599 (2017).

[3] A.E. Clements, A.S. Hurn, \& Z. Li, The effect of transmission constraints on electricity prices. Energy Journal, 38(4), 145-163 (2017)

[4] P.M. Costa, N. Bento, V. Marques, The impact of regulation on a firm's incentives to invest in emergent smart grid technologies. Energy Journal, 38(2), 149-174 (2017)

[5] T.V. Malysheva, Shinkevich, A.I. Kharisova, G.M., Y.V. Nuretdinov, O.R. Khasyanov, I.G. Nuretdinov, N.A. Zaitseva, S.S. Kudryavtseva, The Sustainable Development of Competitive Enterprises through the Implementation of Innovative Development Strategy. International Journal of Economics and Financial Issues, 6(1), 185-19 (2016)

[6] T.V. Malysheva, A.I. Shinkevich, S.S. Ostanina, E.L. Vodolazhskaya, V.O. Moiseyev, Perspective directions of improving energy efficiency on the meso and micro levels of the economy. Journal of Advanced Research in Law and Economics, 1(15), 75-83 (2016)

[7] A. Wasiak, O. Orynycz, Energy Efficiency of a Biofuel Production System. Journal of Management and Production Engineering Review, 8(1), 60-68 (2017)
[8] A.I. Shinkevich, T.V. Malysheva, L.M. Ostanin, T.V. Muzhzhavleva, E.A. Kandrashina, Organization challenges of competitive petrochemical products production. Espacios, 39(9), 28-41 (2018)

[9] A.I. Shinkevich, T.V. Malysheva, E.N. Ryabinina, N.V. Morozova, G.N. Sokolova, I.A. Vasileva, I.I. Ishmuradova Formation of Network Model of Value Added Chain Based on Integration of Competitive Enterprises in Innovation-Oriented CrossSectorial Clusters. International Journal of Environmental and Science Education, 17, 10347-10364 (2016)

[10] P. Oborski, Integrated monitoring system of production processes. Management and Production Engineering Review, 7(4), 86-96 (2016)

[11] J.G. Masbad, V.M. Noel, R.S. Omega, V. Van Gaitano, A.F. Abatayo, Prioritizing interdependent production processes using leontief input-output model Integrated monitoring system of production processes. Management and Production Engineering Review, 7(1), 45-55 (2016)

[12] R. Lundmark, K. Bäckström, P. Oborski, Bioenergy innovation and energy policy. Economics of Innovation and New Technology, 24(8), 755-775 (2015)

[13] B. Radej, J. Drnovšek, G. Begeš, An overview and evaluation of quality-improvement methods from the manufacturing and supply-chain perspective . Advances in Production Engineering and Management, 12(4), 388400 (2017)

[14] F.P. Yin, Q. Gao, X. Ji, Performance modelling based on value analysis for improving product development process architecture. Advances in Production Engineering and Management, 12(1), 17-28 (2017)

[15] M. Gubán, , G. Kovács, \& S. Kot, Simulation of Complex Logistical Service Processes. Management and Production Engineering Review, 8(2), 19-29 (2017)

[16] P. Poutanen, W. Soliman, P. Stahle,. The complexity of innovation: an assessment and review of the complexity perspective. European Journal of Innovation Management, 19(2), 19189-213 (2016)

[17] F.V. Haase, R. Woll, Assessment of Reliability Implementation in Manufacturing Enterprises. Management and Production Engineering Review, 7(2), 12-20 (2016)

[18] P. Río, G. Resch, A. Ortner, S. Busch, F.V. Panzer, C. Haase, R. Woll, A techno-economic analysis of EU renewable electricity policy pathways in 2030. Energy Policy, 104, 484-493 (2017)

[19] C. Dong, C.T. Ng, \& T.C.E. Cheng, lectricity Time-of-Use Tariff with Stochastic Demand. Production and Operations Management, 7 26(1), 64-79 (2017)

[20] A. Bublitz, D. Keles, W. Fichtner, Ananalysis of the decline of electricity spot prices in Europe: Who is to blame? Energy Policyt, 107, 323-336 (2017) 